Sobre a Necessidade de Promover a Prevenção Primária do Traumatismo Craniano

\section{On the Need to Promote the Primary Prevention of} Head Injury

Palavras-chave: Portugal; Traumatismos Crânio-Encefálico; Unidades de Cuidados Intensivos

Keywords: Brain Injuries; Intensive Care Units; Portugal

Está bem documentado o decréscimo do fenómeno da lesão encefálica traumática [traumatismo crâneo encefálico (TCE) major] na população Portuguesa, assente em estudos que têm por base os internamentos hospitalares, documentados pelos códigos da Classificação Internacional de Doenças - Modificação Clínica (CID-MC) e Grupos de Diagnóstico Homogéneos (GDH). Observou-se uma taxa de incidência de 151/100 000 em 1994 e de 137/100 000, em 1996 e 1997, respectivamente. A taxa global de mortalidade, em 1997, foi de 17/100 000. ${ }^{1}$ Usando também metodologias de análise de doentes internados recorrendo a códigos da CID-MC e GDH, verificou-se que durante a década 2000 - 2010, as hospitalizações por lesão encefálica traumática diminuíram em frequência, e a idade dos doentes internados aumentou. As tendências na etiologia do TCE mudaram de acidentes de trânsito para quedas, o que ilustra a necessidade de prestar atenção às faixas etárias mais velhas e de implementar medidas preventivas para reduzir o TCE. A prevenção primária de acidentes da estrada parecia estar a ser eficaz, mas foi invocada a necessidade de melhorar a acessibilidade para idosos. A utilização de Cuidados Intensivos e de procedimentos neurocirúrgicos foi mais difundida, mas as taxas de mortalidade também cresceram. Isto deveu-se possivelmente ao aumento da severidade do TCE, mas também os cuidados pré-hospitalares portugueses melhoraram, tal resultando em que casos que anteriormente seriam letais no pré-hospitalar conseguissem chegar vivos ao hospital, ainda que em estado muito grave; embora sujeitos a tratamento, acabaram por contribuir para o aumento da mortalidade intra-hospitalar registada. ${ }^{2}$ Os números mais atuais disponíveis de Portugal estão alinhados com a realidade da União Europeia, e evidenciam que a taxa de incidência de lesão encefálica traumática diminuiu para valores na ordem dos 62 - 65/100 000 lano no período 2011 - 2014, e que nesse mesmo período, as taxas de mortalidade mostram também um drástico declínio para valores de 9 - 10/100 000 /ano. $^{3}$

Todavia, o fenómeno do traumatismo craniano medido a nível de internamento hospitalar (TCE major), não é sinónimo necessariamente de que a incidência de traumatismo craniano como fenómeno global esteja a decrescer na comunidade. Podemos estar a conseguir que as consequências que ele tem sejam menores, nomeadamente na sua vertente principal que é a hemorragia intracraniana, mas ele pode continuar a ser frequente demais. Importa consequentemente medir a incidência de traumatismo craniano em sentido lato e global, que resulta da soma dos casos com lesão associada documentada (TCE major - lesões em tomografia computorizada - TC cerebral), com os casos que não têm lesão associada documentada (TCE minor - sem lesões em TC cerebral). Enquanto que as bases de dados de internamento hospitalar fornecerão elementos muitos indicadores do TCE major, no que toca ao TCE minor já não serão elucidativas, visto que não havendo lesões objetiváveis, não resultarão em internamento. No entanto, este grupo de doentes consumirá recursos de avaliação clínica e de meios complementares de diagnóstico e terapêutica (MCDT), nomeadamente TCs, que serão de ter em conta. Acresce ainda que, havendo lesões minor em TC cerebral poderá não se optar por internamento, sendo estes doentes 'omitidos' dos estudos que usam a metodologia de codificação e grupos de diagnósticos homogéneos. Dando como certo que o fenómeno do TCE major está documentado e analisado, será necessário recorrer a outra forma de análise para caracterizar a incidência do TCE minor e do fenómeno de TCE global.

A caracterização da população que acorre às urgências hospitalares, diretamente e transferida de outras instituições, em centros de referenciação terciários portugueses está disponível. No entanto, a análise de incidência fica dificultada pelos vieses de referenciação e ausência de caracterização da área de referência. Num estudo Português, foram contabilizados 2470 doentes com traumatismo craniano a partir do algoritmo de triagem "TCE", "queda" e "grande traumatizado" no período de um ano, verificando-se predomínio feminino (50,7\%); $17,7 \%$ deram entrada no Serviço de Urgência transferidos de outro hospital ou centro de saúde; a população era idosa (média de 60,74 anos, 50,9\% tinham idade igual ou superior a 65 anos); verificou-se aumento do número de casos nos últimos meses do ano (setembro, outubro, novembro, dezembro). A maioria dos TCE's foi ligeiro $(64,5 \%$ com pontuação de 15 na escala de coma de Glasgow) e as causas mais frequentes foram a queda $(73,6 \%)$, acidente de automóvel $(7,6 \%)$, atropelamento $(4,9 \%)$, e acidente de motociclo $(2,5 \%)$. Evidenciavam consumo de álcool $11,9 \%$, e 5,0\% estavam hipocoagulados. Em $77,3 \%$ dos doentes foi requisitado TC cerebral. ${ }^{4}$ Noutro estudo Português, que analisou as indicações de realização de todas as TC's cerebrais durante um ano num hospital com área de referenciação bem definida, verificou-se que o traumatismo craniano foi a situação mais frequente motivadora do exame $(30,11 \%)$, encontrando-se uma taxa de incidência global de traumatismo craniano de $767,48 / 100$ 000/ano e uma taxa de incidência de hemorragia de 76,33/100 000/ano no contexto de trauma. Esta diferença de taxas de incidência de quase dez vezes traduz o impacto do traumatismo craniano minor no dia a dia. ${ }^{5}$ Assim, continua actualmente a ser premente, a promoção de uma cultura de segurança e de prevenção primária do traumatismo craniano, impedindo que ele ocorra. 


\section{REFERENNCIAS}

1. Santos ME, De Sousa L, Castro-Caldas A. Epidemiologia dos traumatismos crânio encefálicos em Portugal. Acta Med Port. 2003;16:71-6

2. Dias C, Rocha J, Pereira E, Cerejo A. Traumatic brain injury in Portugal: trends in hospital admissions from 2000 to 2010. Acta Med Port. 2014;27:349-56.

3. Santos ME, Agrela N. Traumatic brain injury in Portugal: progress in incidence and mortality. Brain Inj. 2019;33:1552-5.
4. Martins, EF. Avaliar o cumprimento do Protocolo Nacional de Traumatismo Crânio-Encefálico no Serviço de Urgência do Hospital de Santo António. Dissertação 2010. [consultado 2019 nov 11]. Disponível em https://repositorio-aberto.up.pt/bitstream/10216/52783/2/Tese $\% 20$ Mestrado\%20\%20Eduarda\%20Martins\%20texto\%20corrido.pdf.

5. Mascarenhas L. Descriptive epidemiology of intracranial hemorrhage patterns and the main complaints motivating brain computed tomography scans in Northern Portugal. Rev Mex Neurocienci. 2019;20:237-43.

Lino MASCARENHAS $\square^{1}$

1. Serviço de Neurocirurgia. Centro Hospitalar de Vila Nova de Gaia-Espinho. Vila Nova de Gaia. Portugal.

Autor correspondente: Lino Mascarenhas. linomasc@gmail.com

Recebido: 06 de dezembro de 2019 - Aceite: 09 de dezembro de 2019 | Copyright @ Ordem dos Médicos 2020

https://doi.org/10.20344/amp.13241

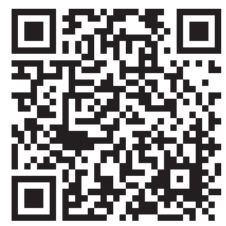

